\title{
Strain Rate Sensitivity of the Additive Manufacturing Material Scalmalloy ${ }^{\circledR}$
}

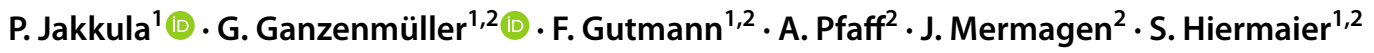

Received: 25 June 2020 / Accepted: 22 March 2021 / Published online: 7 April 2021

(c) The Author(s) 2021

\begin{abstract}
This work investigates the influence of strain rate on the stress/strain behaviour of Scalmalloy. This material is an aluminiumscandium-magnesium alloy, specifically developed for additive manufacturing. The bulk yield stress of the material processed by Selective Laser Melting is approximately $340 \mathrm{MPa}$ which can be increased by heat-treating to approximately $530 \mathrm{MPa}$. These numbers, combined with the low mass density of $2.7 \mathrm{~g} / \mathrm{cm}^{3}$, make Scalmalloy an interesting candidate for lightweight crash-absorbing structures. As this application is inherently dynamic, it is of interest to study the loading rate sensitivity, which is difficult to predict: Al-Sc alloys exhibit classic strain rate sensitivity with an increased yield stress at elevated strain rates. However, $\mathrm{Al}-\mathrm{Mg}$ alloys are known to show the contrary effect, they exhibit less strength as strain rate is increased. To answer the question how these effects combine, we study the dynamic behaviour at four different strain rates ranging from $10^{-3}$ to $1000 / \mathrm{s}$ using servo-hydraulic and split-Hopkinson testing methods. The resulting data is analysed in terms of strain rate sensitivity of tensile strength and failure strain. A constitutive model based on a simplified Johnson-Cook approach is employed to simulate the tensile tests and provides good agreement with the experimental observations.
\end{abstract}

Keywords Aluminium alloy $\cdot$ Dynamic testing $\cdot$ Additive manufacturing $\cdot$ Split-Hopkinson methods

\section{Introduction}

Additive manufacturing (AM) of metal structures allows for producing complex parts with tailored properties. These parts inherit their mechanical behaviour not only from the base material, but also from structural design choices, on a meso-scale between the metal microstructure length scale and the overall dimensions of the parts [1-3]. This allows for the design of light-weight, high-strength structures, and these are increasingly used for safety-relevant applications in aerospace and automotive engineering [4-8]. In these applications, dynamic loading due to crash and impact are routinely encountered. It is therefore a necessary requirement

G. Ganzenmüller

georg.ganzenmueller@inatech.uni-freiburg.de

1 Albert-Ludwigs-Universität Freiburg, Sustainable Systems Engineering, INATECH, Emmy-Noether Str. 2, 79110 Freiburg, Germany

2 Fraunhofer Institute for High-Speed Dynamics, Ernst-Mach-Institut, EMI, Ernst-Zermelo Str. 4, 79104 Freiburg, Germany to know the strain-rate dependency of the base material to quantify crashworthiness.

This work considers the Scandium modified Aluminium-Magnesium alloy AA5028, which is commercialized by APworks and sold under the trade name Scalmalloy. According to the manufacturer, it is based on the $5 \mathrm{xxx}$ series AlMg alloys with an $\mathrm{Mg}$ content of 3.2-4.8 wt\% and Sc $0.02-0.04 \mathrm{wt} \%$ [9]. While the current work does not consider microstructural analysis, related data may be found in [10]. The addition of Scandium increases strength and improves weldability [11]. The bulk yield stress of the as-built material is approximately $350 \mathrm{MPa}$ which can be increased by heat-treating to approximately $550 \mathrm{MPa}$ [9]. These numbers, combined with the low mass density of $2.7 \mathrm{~g} / \mathrm{cm}^{3}$, make AA5028/Scalmalloy an interesting candidate for lightweight crash-absorbing structures. Its strain-rate sensitivity, however, is difficult to predict.

$\mathrm{Al}-\mathrm{Sc}$ alloys exhibit classic strain rate sensitivity with an increased yield stress at elevated strain rates [12]. In contrast, $\mathrm{Al}-\mathrm{Mg}$ alloys are known to show the contrary effect, they exhibit negative strain rate sensitivity, at least up to moderate strain rates of $10^{3} / \mathrm{s}$ [13]. To answer the question how these effects combine in AA5028, we study its dynamic 
behaviour at four different strain rates ranging from $10^{-3}$ to 1000 /s using servo-hydraulic and split-Hopkinson testing methods. Both as-built and heat-treated specimens are investigated, and the resulting data is analysed in terms of the strain-rate dependency of Ultimate Tensile Strength (UTS) and strain at failure. Finally, a simplified Johnson-Cook material model is parametrized to reproduce the experimental findings, allowing for the simulation of dynamic loading events.

\section{Materials and Methods}

\section{Specimens}

A total of 60 raw stock cylinders with dimensions of $\varnothing 20 \times 120 \mathrm{~mm}^{2}$ were produced from a single feedstock by a commercial Laser Beam Melting system (EOS M 400), equipped with a $1 \mathrm{~kW}$ laser unit (YLR-series, Continuous Wave (CW)-laser, wavelength $1070 \mathrm{~nm}$ ). The specimens were printed in a 90 degree orientation to the build plate. All objects were manufactured with $60 \mu \mathrm{m}$ layers with a heated building platform $\left(40^{\circ} \mathrm{C}\right)$. Half of the batch was subjected to a heat treatment of $325^{\circ} \mathrm{C}$ for $4 \mathrm{~h}$, following the powder manufacturer's (APworks) recommendation. The final specimen geometry, according to Fig. 1, was then obtained by CNC machining. This particular specimen geometry was chosen over a standardized geometry to work well with the constraints of our split-Hopkinson tension bar.

\section{Quasi-static and Low Strain Rate Testing}

Tensile testing for the strain rates $0.001 / \mathrm{s}, 0.1 / \mathrm{s}$, and 10 /s were performed using a servo-hydraulic testing machine (Instron 8801), equipped with a $50 \mathrm{kN}$ load cell (Dynacell). Testing was performed in displacement controlled mode with constant cross-head velocities. Nominal specimen strain was evaluated using Digital Image Correlation (2DDIC, GOM Correlate software) with a resolution of 1 pixel $=0.026 \mathrm{~mm}$. A fine speckle pattern with approximate speckle sizes of $0.1 \mathrm{~mm}$ was produced with an airbrush gun. A DIC-based virtual extensometer was defined over a gauge length of $12 \mathrm{~mm}$, i.e., contained entirely within the parallel gauge region. In this way, nominal strain could be evaluated up to the point of failure. From prior experience, the accuracy of the nominal strain measurement is better than $2 \%$ of the indicated value. Additionally, we evaluated the local strain in the necking region. This, however, was only possible for small local strains, as DIC then failed to correctly track deformation field. The beginning of deviation between local strain and extensometer strain was used to define necking strain, i.e., the end of uniform elongation. Deformation images were recorded using a high speed camera (Photron SAZ) with $1024 \times 1024$ resolution at $35 \mathrm{fps}$ to $6000 \mathrm{fps}$, depending on the strain rate. In the following, we always report nominal (engineering) stress, i.e., the ratio of force over the initial value of the specimen's gauge length cross-section.

\section{Dynamic Strain Rate Testing}

The split Hopkinson tension bar (SHTB) used here is sketched in Fig. 2 and described in detail in [14]. Compared to other SHTBs, this setup is optimized for low velocities, low forces and a long pulse duration of $1.2 \mathrm{~ms}$. Force is measured via a pair of conventional strain gauges mounted on the output bar, connected diagonally in a Wheatstone bridge circuit to eliminate bending information. The Wheatstone bridge circuit is driven in constant voltage mode and its output is increased by a factor of 100 using an amplifier with $1 \mathrm{MHz}$ bandwidth. This signal is recorded by a data acquisition (DAQ) card operating at $10 \mathrm{MHz}$ and 16 bit resolution. The conversion factor from strain to force is established via a calibration procedure, wherein a dedicated force sensor is placed between input and output bars, while

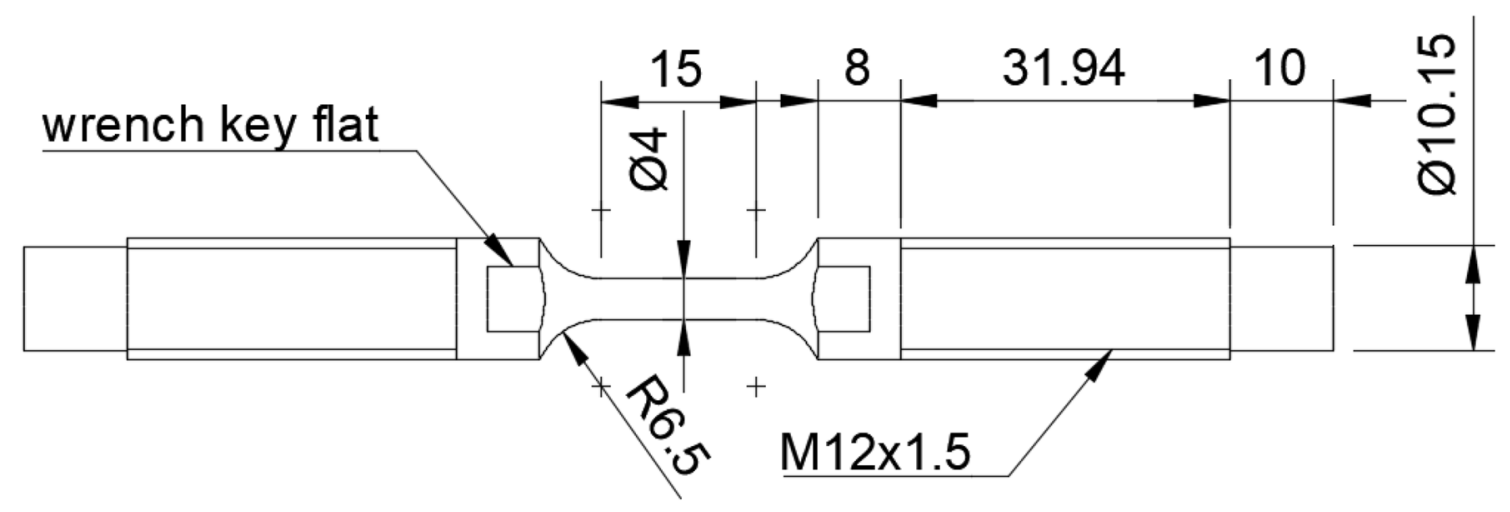

Fig. 1 Specimen geometry with cylindrical gauge region $\varnothing 4 \times 15$. All dimensions are in $\mathrm{mm}$ 


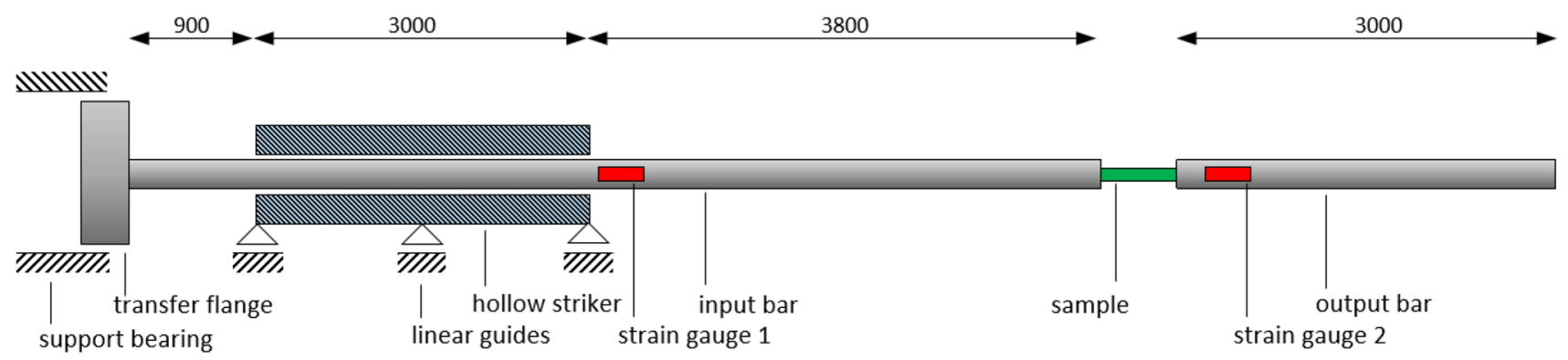

Fig. 2 Sketch of the SHTB setup employed in this work. All dimensions in $\mathrm{mm}$. Input and output bars are $16 \mathrm{~mm}$ diameter aluminium rods. The striker is a hollow aluminium tube of $40 \mathrm{~mm}$ outer diameter

a static load is applied onto the bars. The signal of the force sensor is recorded using the same amplifier and data acquisition card as during a real experiment. The force sensor, in turn is calibrated against the already calibrated load cell in the universal testing machine described above. Thus, the entire force measuring system consisting of strain gauges, amplifier and DAQ card is calibrated, which compensates for any eventual misalignment of the strain gauges or similar constant systematic errors.

The loading pulse generated in the input bar from the impact of the striker to the flange, gives the long pulse duration of $1.2 \mathrm{~ms}$ as shown in Fig. 3A. High-Speed video imaging of the sample is employed (Photron SAZ, $640 \times 280$ pixels, frame rate $100 \mathrm{kHz}, 1 \mathrm{px}=0.067 \mathrm{~mm}$ ) for subsequent optical strain analysis by 2D DIC. Shortly before performing the experiment, a speckle pattern with white and black spray paint was applied to the specimen gauge section in order to provide the necessary contrast for the DIC analysis. The specimens were then directly threaded into the bar ends and $20 \mathrm{~mm}$ inner diameter. Two strain gauges stations on the input bar and output bar measure the incident wave, $\varepsilon_{i n c}$, and transmitted wave, $\varepsilon_{\text {tra }}$

and torqued to $10 \mathrm{Nm}$. The experiment was then conducted by firing the striker against the input flange at a velocity suitable to reach a nominal strain rate of $1000 \pm 100 / \mathrm{s}$ in the sample gauge section. Specimen strain was computed from DIC in the same manner as for the lower strain rates. We note that, due to the rise time of the loading pulse, the target strain rate of $1000 / \mathrm{s}$ is reached after the yield point, see Fig. 3B.

\section{Data Reduction}

Figure 4 shows the nominal stress/strain curves obtained for all combinations of strain rate and specimen type: as-built (untreated) and heat-treated. Each testing series consists of $N=5$ experiments. Within one series, the individual experiments exhibit very little scatter. The characteristic properties ultimate tensile strength, $\sigma_{\max }$ and strain at failure, $\varepsilon_{f}$ are represented using straightforward averages and uncertainty
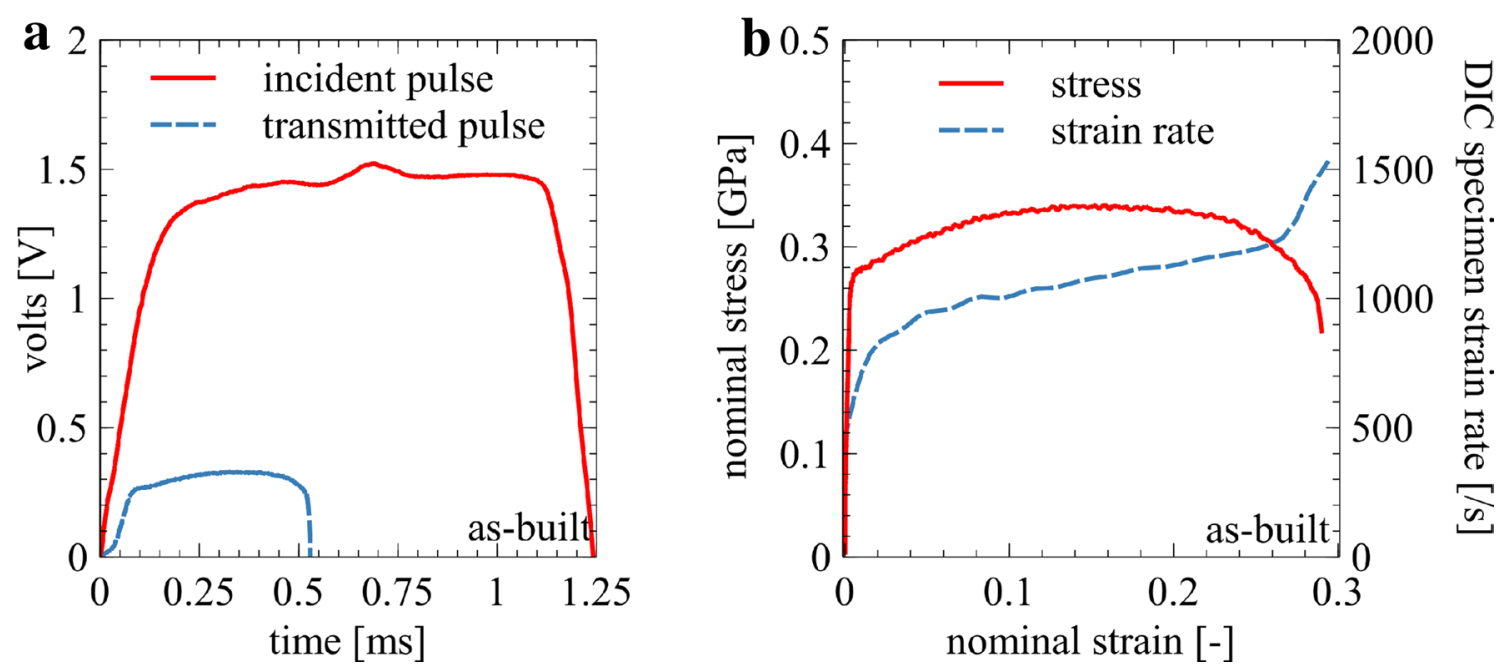

Fig. 3 a Raw data from strain gauge 1 (incident pulse) and strain gauge 2 (transmitted pulse) for an as-built Scalmalloy specimen. b Evolution of nominal strain rate in the specimen's gauge region as computed by DIC 
Fig. 4 Scalmalloy nominal stress-nominal strain plots at different strain rates ranging from $10^{-3}$ to $10^{3} / \mathrm{s}$. Left and right columns are for as-built (non heat-treated) and heattreated specimens, respectively. Note that each experiment set has 5 individual experiments which are shown with differently coloured lines (Color figure online)

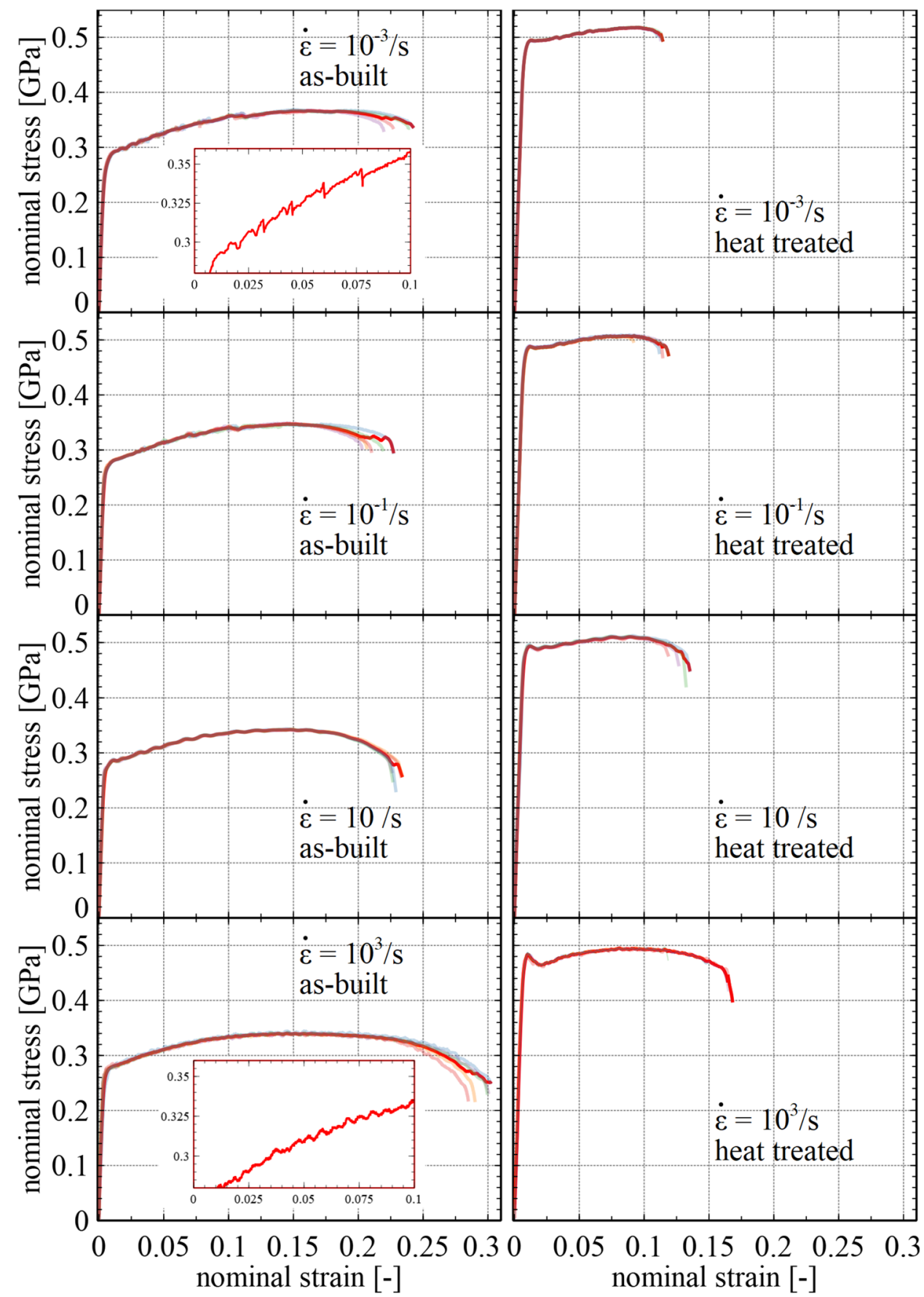

estimates, e.g. for the strength: $\bar{\sigma}_{\max }=\sum_{j=1}^{N} \sigma_{\max j} / N$ and $s\left(\bar{\sigma}_{\max }\right)=\sqrt{\sum_{j=1}^{N}\left(\sigma_{\max , j}-\bar{\sigma}_{\max }\right)^{2} /(N-1)}$.

\section{Results}

The nominal stress/strain graphs obtained by our experiments are shown in Fig. 4. Within one testing series, the individual curves are almost indistinguishable which we attribute to the quality of our SLM process. At quasi-static rates of strain, obvious serrations in the curves are visible. These are presumably due to the Portevin-Le-Chatelier (PLC) effect, which describes the locking of a moving dislocation due to solute $\mathrm{Mg}$ atoms [13]. At higher strain rates, this effect diminishes as the diffusion speed of solute $\mathrm{Mg}$ becomes slow compared to the dislocation speed. Averages for ultimate tensile strength (the maximum of the nominal stress/nominal strain-curve), failure strain, yield strength and necking strain are reported in Table 1 . Note that the 
Table 1 Results for ultimate tensile strength $\sigma_{\max }$, failure strain $\varepsilon_{\text {fail }}$, yield strength and necking strain at different strain rates considered in this work

\begin{tabular}{llllll}
\hline & Strain rate & Max. strength $(\mathrm{MPa})$ & Failure strain $(\%)$ & Yield strength $(\mathrm{MPa})$ & Necking strain $(\%)$ \\
\hline As-built & 0.001 & $368.4 \pm 1.1$ & $23.2 \pm 1.1$ & $263.2 \pm 4.2$ & $17.8 \pm 2.1$ \\
& 0.1 & $348.5 \pm 1.2$ & $21.3 \pm 1.1$ & $260.8 \pm 3.3$ & $16.5 \pm 0.9$ \\
& 10 & $342.6 \pm 0.9$ & $23.0 \pm 0.4$ & $266.7 \pm 1.2$ & $15.9 \pm 0.3$ \\
& 1000 & $342.5 \pm 1.6$ & $29.5 \pm 0.4$ & $269.0 \pm 7.1$ & $23.1 \pm 1.3$ \\
Heat-treated & 0.001 & $518.6 \pm 0.5$ & $11.2 \pm 0.2$ & $465.6 \pm 1.2$ & $10.3 \pm 0.3$ \\
& 0.1 & $508.1 \pm 1.3$ & $11.1 \pm 0.5$ & $470.7 \pm 3.6$ & $10.2 \pm 0.6$ \\
& 10 & $511.0 \pm 1.5$ & $12.8 \pm 0.6$ & $462.8 \pm 1.8$ & $10.8 \pm 0.8$ \\
& 1000 & $497.0 \pm 3.0$ & $15.0 \pm 2.2$ & $477.0 \pm 3.9$ & $14.9 \pm 0.1$ \\
\hline
\end{tabular}

Errors indicate one standard deviation

value of the strain rate at yield is uncertain for the SHTB experiment as yielding occurs during the rise of the loading pulse. Our quasi-static data is in agreement with prior work on Scalmalloy [10], where an UTS of $334 \mathrm{MPa}$ and $540 \mathrm{MPa}$ was reported for as-built and heat-treated specimens, respectively. The failure behavior is brittle for the heat-treated specimens, with almost no necking. As-built specimens exhibit limited necking. Here, the diameter at the failure location is $75 \%$ of the initial value.

\section{Strain-Rate Dependency}

To quantify the strain rate sensitivity, the characteristic quantities given in Table 1 are analysed. The maximum stress is well represented by a relationship proportional to the negative logarithm of the strain rate:

$\sigma_{\max }=\sigma_{0}+a \log (\dot{\varepsilon})$

The constant of proportionality is $a=-4.9 \pm 0.3 \mathrm{MPa}$, and $a=-2.9 \pm 0.3 \mathrm{MPa}$, for as-built and heat-treated Scalmalloy, respectively. Uncertainty estimates are obtained from the residual error of the Levenberg-Marquardt algorithm used for data fitting. The dependence of the strain at failure on strain rate does not follow this simple Johnson-Cook type behaviour. Instead, a Cowper-Symonds relationship appears to better fit the data:

$\varepsilon_{\text {fail }}=\varepsilon_{\text {fail }, 0}\left(1+\alpha(\dot{\varepsilon} \times[\mathrm{s}])^{\beta}\right)$

For as-built specimens, we find $\varepsilon_{\text {fail }, 0}=0.223 \pm 0.005$, $\alpha=0.009 \pm 0.007$, and $\beta=0.51 \pm 0.10$. For heattreated Scalmalloy, we find $\varepsilon_{\text {fail }, 0}=0.109 \pm 0.004$, $\alpha=0.009 \pm 0.007$, and $\beta=0.23 \pm 0.13$.

Within the experimental uncertainty, both the strain at the end of uniform elongation (beginning of neck formation) and the failure strain are unaffected in the strain rate interval $10^{-3}$ to $10 / \mathrm{s}$. At $10^{3} / \mathrm{s}$, however, both strains increase. It is likely that this increase in ductility is the result of adiabatic heating. We conclude this section by noting that Scalmalloy exhibits a weak negative strain rate sensitivity for the UTS. The failure strain, however, increases along with the strain rate (Fig. 5).

\section{Simulation Model}

The data presented in Sect. 3 is employed to parametrize a simplified Johnson-Cook (JC) plasticity model in combination with an explicit Finite Element scheme LS-Dyna (v.11.0, Livermore Software Technology, USA). This JC model only accounts for isotropic hardening but no temperature effects. The strain-rate dependency of the yieldstress is disregarded as it is weak, but more importantly, negative. Softening with increasing strain-rate would lead to strong instabilities in explicit time integration schemes as it promotes localization and necking. Failure is addressed by deleting elements which exceed a given value of effective plastic strain. The failure model is strain-rate sensitive according to the above determined Cowper-Symonds relations, c.f. Eq. 2.

\section{Constitutive Model}

The constitutive model is based on isotropic linear elasticity with Young's modulus $E=70 \mathrm{GPa}$ and Poisson's ratio $v=0.3$. These values are typical of Aluminium alloys and in agreement with experimental data on Scalmalloy [10]. We utilize a $J_{2}$ plasticity model with radial return, based on the yield stress $\sigma_{y}$ according to the simplified JC model:

$\sigma_{y}=\left(A+B \bar{\varepsilon}^{n}\right)$

Here, $\bar{\varepsilon}$ is the accumulated effective plastic strain. Failure is accounted for by deleting those elements which exceed the strain-rate dependent maximum effective plastic strain, 

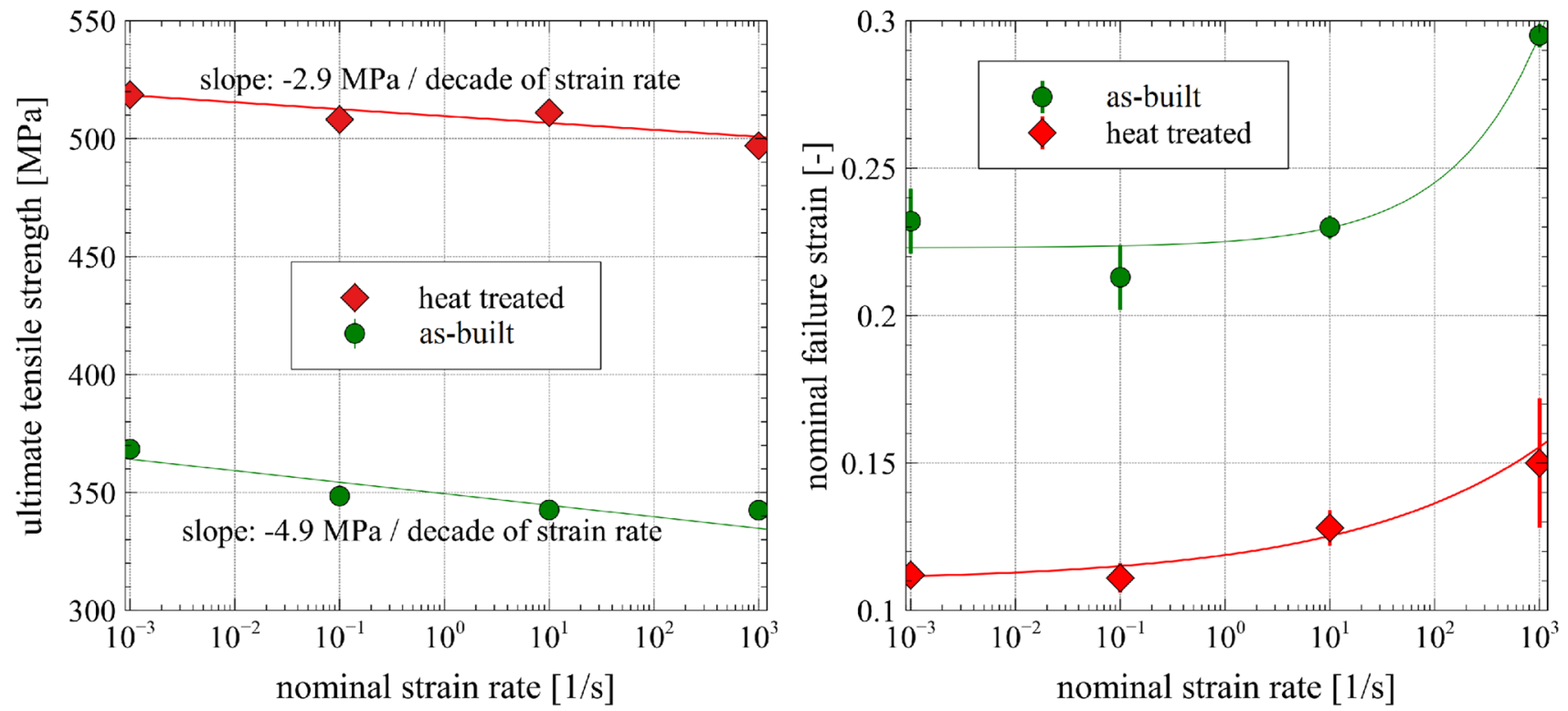

Fig. 5 Analysis of the strain rate dependency of ultimate strength and failure strain. The ultimate strength is proportional to the logarithm of the strain rate, while the failure strain is better described using a Cowper-Symonds relationship, see text.

$\bar{\varepsilon}_{\text {fail }}=\bar{\varepsilon}_{0}\left(1+\alpha(\dot{\varepsilon} \times[\mathrm{s}])^{\beta}\right)$

The Cowper-Symonds parameters $\alpha$ and $\beta$ are taken from Sect. 3. The remaining parameters $A, B$, $n$, and the initial failure strain $\bar{\varepsilon}_{0}$ are determined using an inverse approach, which is described in the following. Note that $\bar{\varepsilon}_{0}$ is not the same as the experimentally determined nominal failure strain $\varepsilon_{f a i l}$ : the former refers to a local quantity under the influence of necking, while the latter describes the average strain of the entire parallel gauge region at failure.

\section{Parametrization of the Constitutive Model}

The reference effective plastic failure strain $\bar{\varepsilon}_{0}$, corresponding to a strain rate of $10^{-3} / \mathrm{s}$ as well as the JC parameters $A, B$, and $n$ are found by an inverse approach: we use the optimization package LS-Opt (v.6.0.0, Livermore Software Technology, USA) in combination with LS-Dyna to simulate tensile testing of the specimen described in Fig. 1. Discretization is performed in a $2 \mathrm{~d}$ axis-symmetric coordinate system with quadrilateral elements of typical size $0.1 \mathrm{~mm}$, which has been established through a convergence study. The simulation output, engineering stress and engineering strain (average of the parallel gauge section) are optimized to agree with the experimental data obtained at strain rate $10^{-3} / \mathrm{s}$. The resulting parameters are summarized in Table 2. The simulated tensile curves are compared to experiments in Fig. 6. The agreement at $\dot{\varepsilon}=10^{-3} / \mathrm{s}$ is good, which shows that the JC model is an apt choice for this material. While the simulation prediction at $\dot{\varepsilon}=10^{3} / \mathrm{s}$ is satisfactory, it overestimates the strength by $\approx 5$ $\%$ in both cases, due to the neglect of the weak negative strain rate sensitivity.

\section{Discussion and Conclusion}

This work investigated the strain rate sensitivity of the $\mathrm{Sc}-\mathrm{Al}-\mathrm{Mg}$ alloy Scalmalloy, which is specifically used for additive manufacturing purposes. Here, bulk tensile specimens obtained via Selective Laser Melting and machined to final dimensions were used. Using a combination of servohydraulic and split-Hopkinson methods, tensile tests ranging from $10^{-3}$ to $10^{3} / \mathrm{s}$ were performed. It was found that the Ultimate Tensile Strength decreases weakly $(\sim 5 \mathrm{MPa} / \mathrm{dec}-$ ade of strain rate) with increasing strain rate, while the yield strength remains constant. Contrary, the failure strain was observed to increase along with rising strain rate. This effect is likely a consequence of adiabatic heating. In general, thermal softening leads to both an increase in ductility as well as a reduction of strength. The observation for Scalmalloy,
Table 2 Parameters of the Johnson-Cook plasticity and failure model for heat-treated and as-built Scalmalloy

\begin{tabular}{lllllll}
\hline Type & $A[\mathrm{MPa}]$ & $B[\mathrm{MPa}]$ & $n$ & $\bar{\varepsilon}_{0}$ & $\alpha$ & $\beta$ \\
\hline As-built & 198 & 400 & 0.332 & 0.41 & 0.009 & 0.51 \\
Heat-treated & 399 & 362 & 0.345 & 0.13 & 0.009 & 0.13 \\
\hline
\end{tabular}




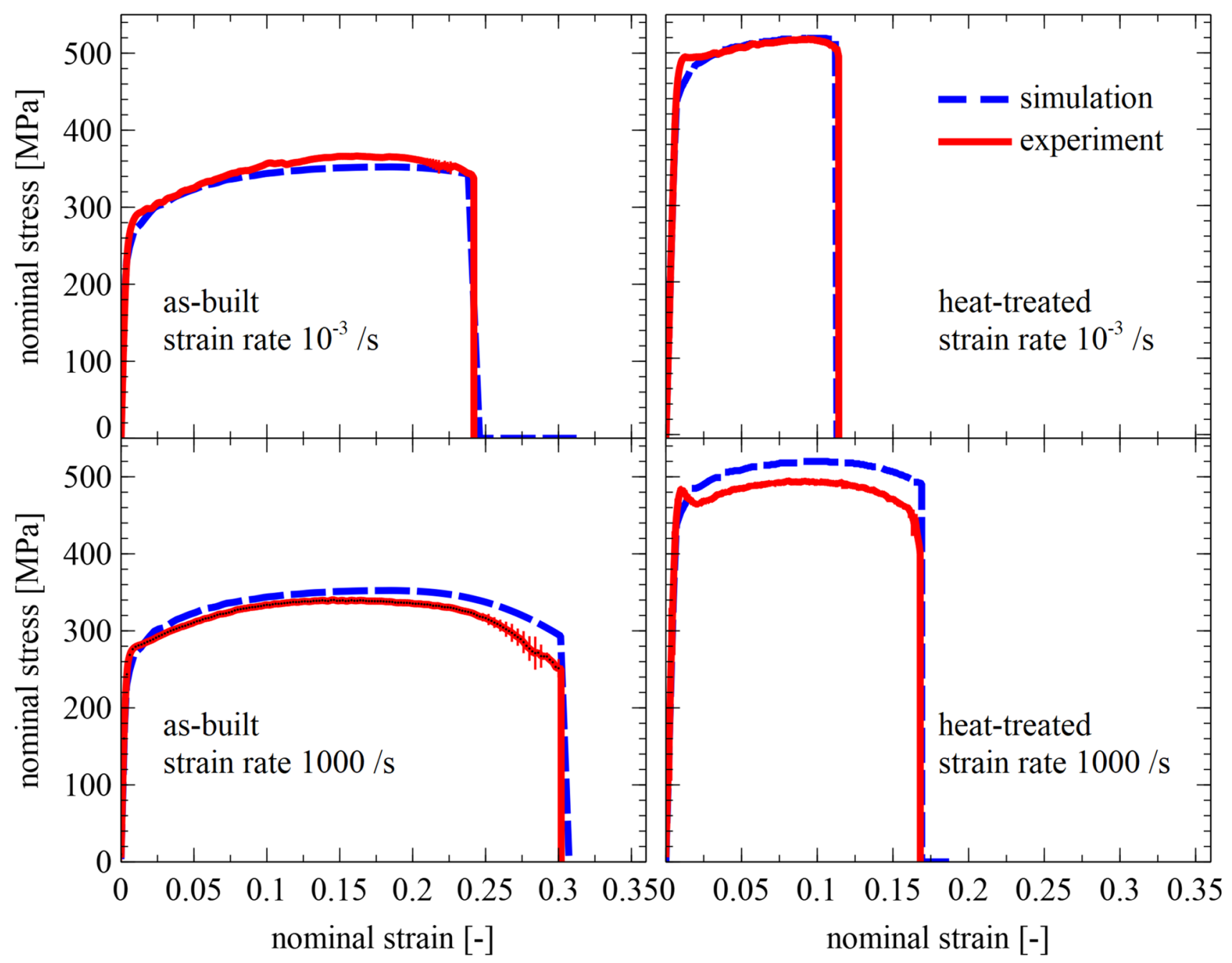

Fig. 6 Comparison between simulation results with the Johnson-Cook model (blue dashed curves) and the experimental data (red curves). The left column is for as-built Scalmalloy, the right column is for the heat-treated material (Color figure online)

that UTS decreases slightly with strain rate, might therefore be the combined effect of both strain rate hardening-as encountered for many metals - and thermal softening. However, the fact that yield stress is unaffected by strain rate, c.f. Table 1, suggests that Scalmalloy shows no strain rate hardening at constant temperature, as adiabatic heating is not relevant at initial yield. The experiments reported here cannot separate these effects in practice, so we have to restrict our finding to an apparent weak decrease in UTS. Additional experiments that quantify the effects of varying temperature at constant strain rate are required to resolve this ambiguity.

To demonstrate the practical applicability of the data reported here, a constitutive model based on the Johnson-Cook plasticity model and a simple strain-rate dependent failure criterion was parametrized and shown to agree well with the experimental data.

This work addresses two important questions. From a practical point of view, this light-weight, yet high strength, aluminium alloy lends itself for safety-relevant applications which include crash and impact scenarios. Our work provides the necessary data and a model to design and simulate such structures, including the effects of strain rate. On the other hand, from a more scientific point of view, it is interesting to see how different strain rate effects of $\mathrm{Sc}$ and $\mathrm{Mg}$ combine in one aluminium alloy: for moderate strain rates $<\approx 10^{3}$, the addition of $\mathrm{Mg}$ mainly leads to negative strain-rate sensitivity [13], while the addition of Sc incurs a pronounced positive strain rate sensitivity [15] for the UTS. For Scalmalloy, with alloying values of $4.4 \%$ $\mathrm{Mg}$ and $0.73 \% \mathrm{Sc}$ by weight [10], these effects appear to mutually cancel out. We note that the observations made here only apply to strain rates of $1000 / \mathrm{s}$ and below. One may speculate that, for even higher strain rates, a changeover from positive to negative strain rate exists, as is the case for the Al-Mg 5021 alloy [16]. 
Acknowledgements We acknowledge funding from Carl-Zeiss Foundation, grant title Skalenübergreifende Charakterisierung robuster funktionaler Materialsysteme.

Funding Open Access funding enabled and organized by Projekt DEAL.

Open Access This article is licensed under a Creative Commons Attribution 4.0 International License, which permits use, sharing, adaptation, distribution and reproduction in any medium or format, as long as you give appropriate credit to the original author(s) and the source, provide a link to the Creative Commons licence, and indicate if changes were made. The images or other third party material in this article are included in the article's Creative Commons licence, unless indicated otherwise in a credit line to the material. If material is not included in the article's Creative Commons licence and your intended use is not permitted by statutory regulation or exceeds the permitted use, you will need to obtain permission directly from the copyright holder. To view a copy of this licence, visit http://creativecommons.org/licenses/by/4.0/.

\section{References}

1. Chekurov S, Metsä-Kortelainen S, Salmi M, Roda I, Jussila A (2018) The perceived value of additively manufactured digital spare parts in industry: an empirical investigation. Int J Prod Econ 205:87-97. https://doi.org/10.1016/j.ijpe.2018.09.008

2. Mitchell A, Lafont U, Hołyńska M, Semprimoschnig C (2018) Additive manufacturing-a review of $4 \mathrm{D}$ printing and future applications. Addit Manuf 24:606-626. https://doi.org/10.1016/j. addma.2018.10.038

3. Rashed MG, Ashraf M, Mines RAW, Hazell PJ (2016) Metallic microlattice materials: a current state of the art on manufacturing, mechanical properties and applications. Mater Design 95:518533. https://doi.org/10.1016/j.matdes.2016.01.146

4. Ozdemir Z, Hernandez-Nava E, Tyas A, Warren JA, Fay SD, Goodall R, Todd I, Askes H (2016) Energy absorption in lattice structures in dynamics: experiments. Int J Impact Eng 89:49-61. https://doi.org/10.1016/j.ijimpeng.2015.10.007

5. Tsouknidas A, Pantazopoulos M, Katsoulis I, Fasnakis D, Maropoulos S, Michailidis N (2016) Impact absorption capacity of 3D-printed components fabricated by fused deposition modelling. Mater Design 102:41-44. https://doi.org/10.1016/j.matdes.2016. 03.154

6. Li S, Zhao S, Hou W, Teng C, Hao Y, Li Y, Yang R, Misra RDK (2016) Functionally graded Ti-6Al-4V meshes with high strength and energy absorption. Adv Eng Mater 18:34-38. https://doi.org/ 10.1002/adem.201500086

7. Tancogne-Dejean T, Spierings AB, Mohr D (2016) Additivelymanufactured metallic micro-lattice materials for high specific energy absorption under static and dynamic loading. Acta Mater 116:14-28. https://doi.org/10.1016/j.actamat.2016.05.054

8. Brennan-Craddock J, Brackett D, Wildman R, Hague R (2012) The design of impact absorbing structures for additive manufacture. J Phys 382:012042. https://doi.org/10.1088/1742-6596/ 382/1/012042

9. Vorel M, Hinsch S, Konopka M, Scheerer M (2017) AlMgSc alloy 5028 status of maturation 2017. p. 9 pages. Publisher: Proceedings of the 7th European Conference for Aeronautics and Space Sciences. Milano, Italy, 3-6 july 2017, https://doi.org/10.13009/ EUCASS2017-633

10. Koutny D, Skulina D, Pantělejev L, Paloušek D, Lenczowski B, Palm F, Nick A (2018) Processing of Al-Sc aluminum alloy using SLM technology. Procedia CIRP 74:44-48. https://doi.org/10. 1016/j.procir.2018.08.027

11. Royset J (2007) Scandium in aluminium alloys: physical metallurgy, properties and applications. Metall Sci Technol 25:2

12. Lee WS, Chen TH (2006) Dynamic mechanical response and microstructural evolution of high strength aluminum-scandium (Al-Sc) alloy. Mater Trans 47:355-363. https://doi.org/10.2320/ matertrans.47.355

13. Yamada H, Kami T, Mori R, Kudo T, Okada M (2018) Strain rate dependence of material strength in AA5xxx series aluminum alloys and evaluation of their constitutive equation. Metals 8:576. https://doi.org/10.3390/met8080576

14. Ganzenmüller GC, Blaum E, Mohrmann D, Langhof T, Plappert D, Ledford N, Paul H, Hiermaier S (2017) A simplified design for a split-Hopkinson tension bar with long pulse duration. Proc Eng 197:109-118. https://doi.org/10.1016/j.proeng.2017.08.087

15. Lee WS, Chen TH (2008) Dynamic deformation behaviour and microstructural evolution of high-strength weldable aluminum scandium (Al-Sc) alloy. Mater Trans 49:1284-1293. https://doi. org/10.2320/matertrans.MRA2008032

16. Kami T, Yamada H, Ogasawara N (2018) Dynamic behaviour of $\mathrm{Al}-\mathrm{Mg}$ aluminum alloy at a wide range of strain rates. EPJ Web Conf 183:02028. https://doi.org/10.1051/epjconf/201818302028

Publisher's Note Springer Nature remains neutral with regard to jurisdictional claims in published maps and institutional affiliations. 